University of Texas Rio Grande Valley

ScholarWorks @ UTRGV

\title{
Beyond the Adaptationist Legacy: Updating Our Teaching to Include a Diversity of Evolutionary Mechanisms
}

\author{
Rebecca M. Price \\ University of Washington - Bothell Campus \\ Kathryn E. Perez \\ The University of Texas Rio Grande Valley, kathryn.perez@utrgv.edu
}

Follow this and additional works at: https://scholarworks.utrgv.edu/bio_fac

Part of the Biology Commons, and the Evolution Commons

\section{Recommended Citation}

Rebecca M. Price, Kathryn E. Perez; Beyond the Adaptationist Legacy: Updating Our Teaching to Include a Diversity of Evolutionary Mechanisms. The American Biology Teacher 1 February 2016; 78 (2): 101-108. https://doi.org/10.1525/abt.2016.78.2.101

This Article is brought to you for free and open access by the College of Sciences at ScholarWorks @ UTRGV. It has been accepted for inclusion in Biology Faculty Publications and Presentations by an authorized administrator of ScholarWorks@ UTRGV.For more information, please contact justin.white@utrgv.edu,william.flores01@utrgv.edu. 
shift moved evolutionary biology away from the "adaptationist programme," the term coined by Gould and Lewontin to criticize "just so stories" that assume, but do not test, that traits are adaptive (Pigliucci \& Kaplan, 2000; Nielsen, 2009). For example, Gould and Lewontin argued that the evolution of the small arms in Tyrannosaurus rex could be an artifact of the dinosaur's large body size that the arms grow disproportionately slowly compared with the rest of the body - rather than due to any change in forelimb function from T. rex's ancestor. Gould and Lewontin cautioned that knowing the function of a trait does not mean that the trait arose from natural selection.

A more recent example of incorrectly inferring that a functional trait is adaptive concerns two genes (microcephalin and ASPM) that affect human brain size (reviewed in Nielsen, 2009). These genes are probably under positive selection because they have a higher rate of nonsynonymous mutations than of synonymous mutations, which suggests that changes in gene function are maintained in the population through selection (Nielsen, 2009). Researchers jumped to the adaptationist conclusion that these genes were responsible for increasing brain size and intellect in human evolution. But subsequent research tested - and cast doubt on - this adaptationist story. The variations in the genes are not associated with intellect, and the increase in brain size predicted by the genes would have occurred within the past 3000-6000 years - a time frame over which fossil evidence shows that human brain size has remained stable (Nielsen, 2009).

Today, if a trait is hypothesized to have evolved from natural selection, that hypothesis must be rigorously tested by documenting its function and also by exploring how the trait's function has been maintained throughout evolutionary history and among many lineages (Coddington, 1988; Nielsen, 2009). Furthermore, the trait must be studied in the context of the whole organism and the many evolutionary tradeoffs that affect an individual (Linde-Medina \& Diogo, 2014). Evolutionary biologists continue to debate how much biodiversity is the product of natural selection (Nielsen, 2009; Pigliucci \& Müller, 2010; Laland et al., 2014). However, as Gould and Lewontin (1979) predicted, the debate now centers on the relative importance of, and interactions among, all evolutionary processes - including, but not limited to, genetic drift, evo-devo, and natural selection (Pigliucci \& Müller, 2010; Laland et al., 2014).

\section{O An Adaptationist Legacy}

\section{Does Evolution Education Research Reflect Scientific Research on Evolution?}

In evolution education, there is a well-established literature on student understanding of natural selection (e.g., Anderson et al., 2002; Gregory, 2009; Nehm et al., 2012), but little has been documented about how students understand other evolutionary processes. A recent ERIC search reveals the extent to which this literature has traditionally emphasized natural selection (Table 1), with only $6 \%$ of articles addressing the other evolutionary processes that we consider in this article. However, recent studies that provide tools (concept inventories; see Appendix) for measuring student understanding of different evolutionary processes (Andrews et al., 2012; Hiatt et al., 2013; Perez et al., 2013; Abraham et al., 2014; Price et al., 2014) begin to document how students (mis)interpret evolutionary processes other than natural selection.

\section{Do Science Standards Reflect Current Evolutionary Research?}

To examine whether teaching standards reflect the field of evolution research by including evolutionary processes other than natural selection, we examined three sets of standards for K-12 education and one set for college: the AP standards (College Board, 2012); AAAS Project 2061 (AAAS, 2009); the K-12 Framework (National Research Council, 2012); and the BioCore guide (Brownell et al., 2014), a set of learning objectives for undergraduate curricula that expands on the core concepts identified in the Vision and Change report (AAAS, 2011). Evolution is prominent in all these documents.

Evolutionary mechanisms other than natural selection are not prominent. High school standards emphasize natural selection in a way that reflects the adaptationist programme that Gould and Lewontin critiqued 35 years ago (Gould \& Lewontin, 1979; Nielsen, 2009). They feature one or more statements about the importance of evolution, but with an emphasis on natural selection (e.g., "Evolution is a change in the genetic makeup of a population over time, with natural selection its major driving mechanism"; College Board, 2012, p. 8). The AAAS Project 2061 includes genetic drift and natural selection, but no other evolutionary processes. The $\mathrm{K}-12$ framework omits discussion of any process other than natural selection (National Research Council, 2012).

The AP standards are the only set of high school standards that we analyzed that includes even one concept from evo-devo, stating that "Developmental gene sequences have an evolutionary origin and are conserved across species, for example, HOX genes are present in genome sequences from Drosophila to humans" (College Board, 2012, p. 60). Unfortunately, this statement is followed by the claim that "Errors or changes in regulation of genes involved in development often lead to severe, detrimental and even bizarre consequences" (College Board, 2012, p. 60). This qualification undermines the core evo-devo concept that changes in the regulation of genes are an important source of evolutionary novelty (Hiatt et al., 2013).

At the college level, the BioCore Guide is more even-handed, giving equal billing to several processes that lead to evolution; for example, "Changes in allele frequencies are caused by random and nonrandom processes - specifically mutation, natural selection, gene flow, and genetic drift. Not all of these changes are adaptive" (Brownell et al., 2014, p. 206). This standard also includes one out of the six core concepts of evo-devo and has the most integration of the foundational development concepts necessary to understand evodevo (Hiatt et al., 2013).

In contrast to the way in which genetic drift and evo-devo are treated in the standards, the treatment of dominance relationships among allelic pairs more accurately reflects the current state of genetics research (Allchin, 2005; Redfield, 2012). None of the frameworks that we analyzed referenced dominance relationships in allelic pairs specifically, although they all include basic principles of transmission genetics. A curriculum that focuses first on big-picture genomics, and then focuses on the origin of variation and the interaction between genotype and phenotype, results in a much more sophisticated, 21 st-century concept of genetics (Redfield, 2012). The more traditional approach teaches Mendelian genetics, then meiosis, and then genetic properties of chromosomes. Redfield (2012) cautions that this traditional approach can inadvertently promote thinking about genetics as a black box. For example, students can take away the idea that 
Table 1. ERIC (Education Resources Information Center, http://eric.ed.gov/) search about key evolutionary processes, performed on May 2, 2015. Search results overestimate the number of relevant articles, because they were not analyzed to determine how the topic was addressed or how instruction on the topic was recommended. Categories may overlap; $\mathrm{N}=1075$ articles.

\begin{tabular}{|c|c|c|}
\hline Search Term & Number of Articles Found & Percentage of Total Articles \\
\hline Natural selection & 1016 & 95 \\
\hline Genetic drift & 22 & 2 \\
\hline Evo-devo & 6 & 0.6 \\
\hline Dominant gene (or allele) ${ }^{a}$ & $33(14)^{b}$ & $3(1)$ \\
\hline
\end{tabular}

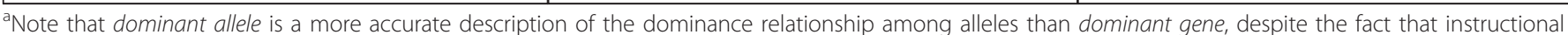

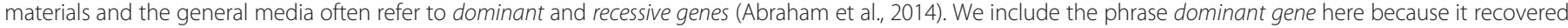
more articles than the phrase dominant allele.

${ }^{b}$ Four articles include both dominant gene and dominant allele.

usually a trait is affected by only a single gene, or that a gene affects only one trait, among other inaccurate ideas about the interaction of genotype and phenotype.

Taken together, our review of the research literature and teaching standards indicate that evolution education research and instruction, unlike evolution research, is still framed by the adaptationist programme. As educators, we need to expand our scope to encompass the full complexity of evolution.

\section{Consequences}

Despite the fact that instructors in high school and college teach other evolutionary processes (regardless of their omission from standards documents), college students continue to oversimplify evolution: they consistently fall into the adaptationist programme by failing to recognize evolutionary processes other than natural selection (Andrews et al., 2012; Beggrow \& Nehm, 2012; Hiatt et al., 2013; Perez et al., 2013; Abraham et al., 2014; Price et al., 2014). Often, they go so far as to conflate the word evolution with natural selection (Jakobi, 2010; Andrews et al., 2012; Hiatt et al., 2013; Abraham et al., 2014).

\section{O Evolutionary Concept Inventories: Pattern \& Process}

The number of concept inventories that address evolutionary topics has been growing as the utility of these tools has become more widely recognized. In addition to the groundbreaking Concept Inventory of Natural Selection (Anderson et al., 2002), instruments have been developed to assess tree-thinking (Baum et al., 2005), genetics (Bowling et al., 2008a, b; Smith et al., 2008), and macroevolution (Nadelson \& Southerland, 2010; Novick \& Catley, 2012). More recently, three concept inventories were developed to help improve instruction about a diversity of evolutionary processes. These instruments measure how students understand genetic drift (GeDI; Price et al., 2014), dominance in allelic pairs (DCI; Abraham et al., 2014), and evo-devo (EvoDevoCI; Perez et al., 2013). This list of concept inventories represents only the evolutionary concept inventories of which we know - we hope that more will be developed and widely distributed to teach the true breadth of evolutionary processes. Like the Concept Inventory of Natural Selection and the genetics inventories, the new instruments on genetic drift, dominance relationships, and evo-devo focus on the process of evolution, rather than solely interpreting patterns of evolution.

\section{O Misconceptions about Many Evolutionary Mechanisms}

One of the challenges of teaching evolution is that students can simultaneously hold accurate ideas - sometimes called "key concepts" (e.g., Nehm \& Reilly, 2007; Nehm \& Schonfeld, 2008; Price et al., 2014); and inaccurate ideas - sometimes referred to as "misconceptions" (Nehm \& Reilly, 2007; Nehm et al., 2010; Crowther \& Price, 2014; Leonard et al., 2014). Previous studies found that many of the misconceptions that students had about genetic drift, dominance, and evo-devo were related to misconceptions about natural selection (summarized in Nehm \& Reilly, 2007; Gregory, 2009; Nehm et al., 2010; Table 2).

Results from the GeDI, DCI, and EvoDevoCI indicate that students rely on explanations of natural selection to the exclusion of other evolutionary mechanisms, for example either defining genetic drift as natural selection or saying that genetic drift is not evolution because it does not lead to directional change that results in an increase in fitness (Table 2). Therefore, in addition to misconceptions about their target processes, the three concept inventories that we review here incorporate misconceptions about natural selection as distractors, including the fact that students over-rely on natural selection as an explanation.

After analyzing these results, we began to wonder whether students' understanding of natural selection impedes their understanding of these other evolutionary mechanisms. We predicted that students who performed poorly on the CIs would frequently choose distractors that described a misconception about natural selection. To test this prediction, we used data from the pertinent questions (those with distractors based on misconceptions about natural selection) of the GeDI (eight questions, $N=691$; Price et al., 2014), the DCI (nine questions, $\mathrm{N}=681-711$; Abraham et al., 2014), and the EvoDevoCI (seven questions, $N=539$; Perez et al., 2013). These data were obtained during the final stage of the validation process for these instruments. The CIs were typically administered in the first week of classes before receiving instruction about the topic (e.g., students who took the GeDI had not received instruction about genetic drift in that class). 
Table 2. Misconceptions about natural selection that appear in concept inventories (CI) about genetic drift, dominance, and evo-devo. For extensive explanations of these misconceptions and student examples of them, see Andrews et al. (2012), Hiatt et al. (2013), and Abraham et al. (2014).

\begin{tabular}{|l|l|}
\hline CI & $\begin{array}{l}\text { Misconceptions about Natural Selection That Appear When Students Discuss Other } \\
\text { Evolutionary Processes }\end{array}$ \\
\hline Genetic drift & $\begin{array}{l}\text { Genetic drift is natural selection/acclimation to the environment that results from a need to } \\
\text { survive. }\end{array}$ \\
\hline & Genetic drift is not evolution because it does not lead to directional change that increases fitness. \\
\hline & $\begin{array}{l}\text { Natural selection is always the most powerful mechanism of evolution, and it is the primary agent } \\
\text { of evolutionary change. }\end{array}$ \\
\hline Dominance & Dominant alleles always increase in frequency in a population. \\
\hline & Dominance is related to the selective advantage of an allele or allelic pair. \\
\hline Evo-devo & Heterozygotes always have a selective advantage over other genotypes. \\
\hline & $\begin{array}{l}\text { Natural selection is always the preferred explanation, even when students are prompted to invoke } \\
\text { more appropriate evo-devo mechanisms. }\end{array}$ \\
\hline & $\begin{array}{l}\text { Characteristics that are not used by the organism are lost because they are not used, not because } \\
\text { of the loss of maintenance selection. }\end{array}$ \\
\hline & $\begin{array}{l}\text { Evolution proceeds through the inheritance of acquired characteristics (not including potentially } \\
\text { legitimate examples such as the genetic assimilation of induced phenotypes, the assimilation } \\
\text { of learned behaviors, or inheritance of epigenetic modifications). }\end{array}$ \\
\hline & \begin{tabular}{l} 
Evolutionary stasis occurs only when stabilizing or positive selection does not occur. \\
\hline
\end{tabular} \\
\hline & $\begin{array}{l}\text { Lack of understanding of population-level processes. For example, attributing evolutionary } \\
\text { adaptation, the population-level process, to an individual. }\end{array}$ \\
\hline
\end{tabular}

\section{O Students Apply Misconceptions about Natural Selection to Other Evolutionary Processes}

In this section, we describe the GeDI, DCI, and EvoDevoCI in detail. We discuss the format and summarize the content of each, and then we use descriptive statistics of published data to record the frequency with which students chose misconceptions about natural selection to explain the target concepts (Figure 1). We found that students who had the lowest understanding of the target concept usually chose answers that contained misconceptions about natural selection.

\section{Genetic Drift Inventory (GeDI)}

The GeDI (Price et al., 2014) is a true-false instrument with 22 questions in which students evaluate whether or how genetic drift is occurring in four different scenarios. The instrument focuses on four key concepts of genetic drift (Price et al., 2014), and the distractors are drawn from a series of misconceptions that undergraduate biology students hold about genetic drift (Andrews et al., 2012), such as the idea that genetic drift occurs only in small populations. The process of validating the GeDI was focused on upper-division biology majors.

We determined whether student performance on questions with distractors that inaccurately represented natural selection was the same as student performance on the overall CI. The results are consistent with our prediction: students who understood more about the evolutionary process being evaluated chose misconceptions about natural selection less frequently. However, even high-performing students sometimes chose misconceptions about natural selection as their preferred explanation.

For example, from the GeDI, we extracted answers from three true-false questions that assessed whether students held the misconception that genetic drift is natural selection/acclimation to the environment that results from a need to survive (Table 2 and Figure 1; Andrews et al., 2012). In this case, Andrews et al. (2012) found that students who held this misconception were often inaccurately defining natural selection as acclimation to the environment (Gregory, 2009; Nehm et al., 2012), so the true-false statements in the GeDI include both ways in which students expressed this misconception (Figure 1). In our sample, students chose the incorrect answer in these three questions frequently. We examined the results for these three questions to consider how students of low, medium, and high understanding of genetic drift answered them, with understanding quantified as performance on the other questions in the GeDI. We found that $67 \%, 70 \%$, and $85 \%$ of the low-performing students chose the misconception on questions 5, 6, and 8; but only 39\%,60\%, and $52 \%$ of the high-performing students did (Figure 1).

\section{Dominance Concept Inventory (DCI)}

The DCI (Abraham et al., 2014) is a 16-item instrument that uses multiple-choice and true-false questions to evaluate how students understand that Mendelian dominance and evolution are two separate 


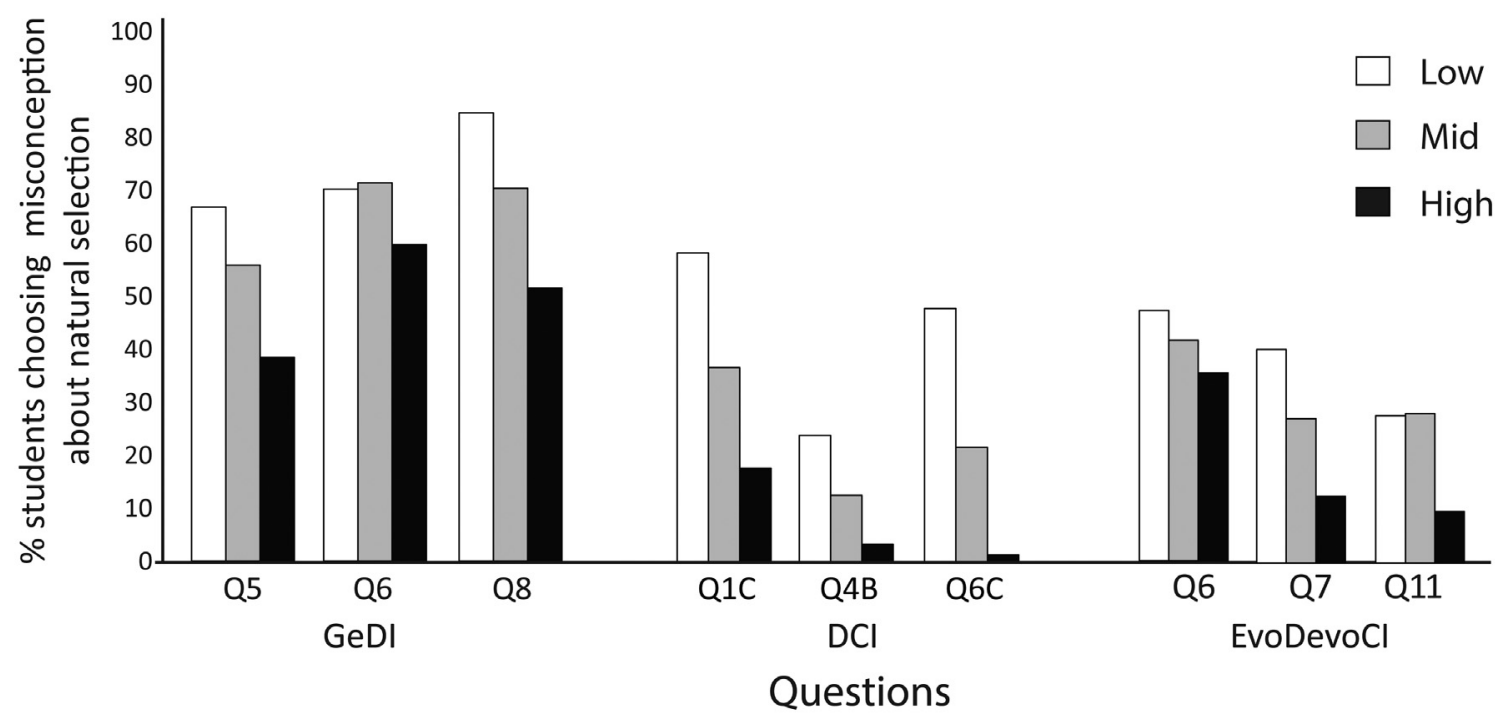

Figure 1. Student performance as defined by scores on the GeDI, DCl, and EvoDevoCl (see text); the questions assessed here were removed from the total score to remove interdependency. The student performance categories divide the pool of tested students roughly into thirds but follow natural breaks in the data; as such, they vary across inventory and are defined as follows: GeDI low (21-47\%), mid (53-68\%), high (74-100\%); DCl low (5-40\%), mid (45-60\%), high (65-90\%); and EvoDevoCl low (0-18\%), mid (27-36\%), high (45-91\%). These GeDI questions assess the misconception that genetic drift is natural selection (Price et al., 2014), for example probing whether genetic drift describes individuals' need to "adjust" to the environment or whether they are best suited for survival. These DCl questions assess the misconception that dominant alleles always increase in frequency in a population (Abraham et al., 2014). They are true-false questions asking whether a dominant allele will necessarily increase in frequency, whether a recessive allele will decrease in frequency, and whether a recessive allele will necessarily go extinct. The EvoDevoCl questions assess the misconception that natural selection is always the preferred explanation, even when students are prompted to invoke more appropriate evo-devo mechanisms (Perez et al., 2013) for three different evo-devo concepts.

concepts. As has been documented in The American Biology Teacher and elsewhere, students often mistakenly assume that a dominant allele will be most common (Collins \& Stewart, 1989; Heim, 1991; Donovan, 1997; Allchin, 2000), that it will increase in frequency (e. g., Allchin, 2000; Christensen, 2000), and that it is selectively advantageous (e.g., Heim, 1991; Allchin, 2000). The DCI also addresses the misconception that heterozygotic allelic pairs are selectively advantageous (Abraham et al., 2014). The validation process for the DCI included students in both introductory and advanced biology classes.

Because the DCI measures students' ability to distinguish dominance from natural selection, their performance on the $\mathrm{CI}$ has to be related to their ability to recognize misconceptions about natural selection. Here, we depict data from three of the true-false questions that assessed whether students held the misconception that dominant alleles always increase in frequency in a population (Table 2 and Figure 1). Often, students who hold this misconception inaccurately conclude that a trait favored by natural selection will also always increase in frequency - that processes like genetic drift, evo-devo, or genomic hitchhiking cannot lead to the decrease of a favorable trait (Abraham et al., 2014). We found that 58\%, 24\%, and $48 \%$ of the low-performing students chose the misconception on questions $1 C$, $4 \mathrm{~B}$, and $6 \mathrm{C}$; but only $18 \%, 3 \%$, and $1 \%$ of the high-performing students did (Figure 1). The improvement seen from the lowest- to highest-performing students is particularly great in the DCI, implying that this particular misconception may be easier to overcome than the other two misconceptions represented in Figure 1.

\section{EvoDevoCI}

The EvoDevoCI (Perez et al., 2013) is an 11-item multiple-choice instrument with vignettes that address five core concepts of evodevo and the misconceptions associated with them (Hiatt et al., 2013). For example, when asked to reason about the idea that small changes in regulatory genes can lead to large changes in phenotype, students often incorrectly state that phenotypic change can occur only when genes appear or disappear in the genome. The validation process for the EvoDevoCI included a broad range of college students, from freshmen through seniors, for life sciences majors as well as nonmajors.

From the EvoDevoCI, we extracted answers from three of the multiple-choice questions that assessed whether students held the misconception that natural selection is always the preferred explanation, even when students are prompted to invoke more appropriate evo-devo mechanisms (Table 2). When we examined the results for these questions separately, we found that $46 \%, 39 \%$, and $27 \%$ of the low-performing students chose this misconception on questions 6,7 , and 11 , respectively; $34 \%, 12 \%$, and $9 \%$ of the high-performing students did (Figure 1). These questions covered different evo-devo concepts, including that evolution can occur by changes in gene regulation, that mutations which are less pleiotropic (have fewer roles in development) are more likely to evolve, and that developmental variation (rather than simple phenotypic variation) is part of the raw material of natural selection. In general, students with greater understanding of evo-devo 
chose the natural selection misconception less often (11\%, 27\%, and $17 \%$ less).

In a recent article in The American Biology Teacher, Kampourakis and Minelli (2014, p. 493) argue that "evolution makes more sense in light of development." They go on to propose the intriguing hypothesis that learning evo-devo provides a way for students to confront their misconceptions about evolution, specifically teleology and essentialism (Hiatt et al., 2013; Kampourakis \& Minelli, 2014). Our data seem to support this hypothesis, because students with a greater understanding of evo-devo chose this misconception about natural selection less often. However, $76 \%$ of the students who took the EvoDevoCI did so during the first week of introductory-level courses, without having received any college-level instruction about evo-devo. Thus, for this population of students, it seems a stretch to argue that their understanding of evo-devo improves their understanding of natural selection. A stronger test of Kampourakis and Minelli's (2014) prediction would include pretesting and posttesting using the EvoDevoCI in courses that had a significant component of evo-devo.

\section{Implications for Teaching}

This analysis of student performance on CIs about genetic drift, dominance concepts, and evo-devo leads us to a conclusion that needs to be explored further. Many students do not recognize different evolutionary processes - to them, all evolution occurs through natural selection (Andrews et al., 2012; Hiatt et al., 2013; Price et al., 2014). The additional description of the data presented here suggests that many of the challenges students have with learning natural selection are actually challenges about evolution more broadly. Our data demonstrate that students with greater conceptual understanding of a diversity of evolutionary mechanisms display fewer misconceptions about natural selection. Therefore, we propose that a straightforward way to improve understanding of evolution may be to shift the focus of evolution teaching to better balance natural selection with other mechanisms of evolution (for discussion of evo-devo, see Kampourakis \& Minelli, 2014).

This proposal is consistent with an idea from educational psychology called interleaving (reviewed in Rohrer, 2012), which argues that switching between facets of a topic and iteratively revisiting those different facets results in better, long-term learning (e.g., natural selection, dominance in allelic pairs, evo-devo, mutation, genetic drift; then starting again with natural selection). On the other hand, blocking, in which one facet is the focus of many consecutive lessons (e.g., natural selection, natural selection, natural selection; then dominance, dominance, dominance; and so on), leads to short-term learning. Our review of teaching standards and the search results of the literature in Table 1 illustrate that, in evolutionary education, teachers have used blocking more than interleaving and focused on natural selection to the detriment of students' understanding of other evolutionary concepts. We predict that interleaving the teaching of evolutionary mechanisms - including but not limited to natural selection, genetic drift, dominance relationships, and evo-devo - within courses and across curricula will be a strong strategy for success.
Another idea from education research - here borrowing from physics education - is the bridging analogy (Clement, 1993; Singer et al., 2012). In this pedagogical strategy, students begin with a scenario that is both accurate and intuitive. Clement's goal was for students to understand that, when a book rests on a table, the table exerts a force on the book. The intuitive concept is that the book exerts a force on the table, but not vice versa. However, if a book rests on a spring, the students intuitively understand that the book exerts a force on the spring, because the spring collapses. Then Clement showed students a book resting on a thin piece of wood that bent under the book's weight. The thin piece of wood bridges students from thinking of a spring to thinking about a table, because it has properties of both. So, when students reached the target concept and identified the forces exerted on a book resting on a table, they more readily understood the force exerted by the table.

Developing bridging analogies for evolution education can help us reframe challenges to focus on how to move students from their intuitive concepts to a variety of target concepts. Historically, we have focused on students' misconceptions about evolution, emphasizing why their concepts are incorrect but not the aspects of intuition that provide building blocks for more expert understanding (Maskiewicz \& Lineback, 2013). The fact that students apply many of their misconceptions about natural selection to explain other evolutionary processes has an optimistic implication: since there are many different target concepts, there is the potential to develop many different bridging analogies to highlight different aspects of evolution. In evolutionary biology, we know the intuitive concepts that students begin with, and we know the target concepts that are our goals. Our challenge is to identify the bridging analogies.

Students more thoroughly exposed to a diversity of evolutionary processes can use these additional contexts to understand evolution. This strategy may be particularly appropriate for students who are having the hardest time understanding a diversity of evolutionary processes (low- and mid-level performers; Figure 1). We propose that refocusing our teaching to more equally include a diversity of evolutionary processes could result in a better understanding of natural selection and a better understanding of all evolutionary processes.

\section{Acknowledgments}

We thank the National Evolutionary Synthesis Center (NESCent), which funded the EvoCI Toolkit Working Group and made this work possible; we also thank our colleagues who collaborated with us to develop the GeDI, DCI, and EvoDevoCI: Joel K. Abraham, Tessa C. Andrews, Gregory K. Davis, Anna Hiatt, Teresa L. McElhinny, Louise S. Mead, Mark Terry, Anna Thanukos, and Caleb Trujillo; the many experts and students who participated in the development of these instruments; the Biology Education Research Group at the University of Washington; the Wisconsin Teaching Fellows and Scholars program; and faculty of the Department of Biology at the University of Wisconsin La Crosse. The National Evolutionary Synthesis Center is supported by National Science Foundation (NSF) grant no. EF-0905606. Any opinions, findings, conclusions, or recommendations expressed in this material are those of the authors and do not necessarily reflect the views of the NSF. We also thank our reviewers. 


\section{References}

AAAS (2009). Benchmarks On-line. http://www.project2061.org//tools/ benchol/bolframe.html.

AAAS (2011). Vision and Change in Underğraduate Bioloğy Education: A Call to Action. Washington, DC: AAAS.

AAAS (2015). AAAS Science Assessment Website. Available online at http://assessment.aaas.org/.

Abraham, J.K., Perez, K.E. \& Price, R.M. (2014). The Dominance Concept Inventory: a tool for assessing undergraduate student alternative conceptions about dominance in Mendelian and population genetics. CBE Life Sciences Education, 13, 349-358.

Adams, W.K. \& Wieman, C.E. (2011). Development and validation of instruments to measure learning of expert-like thinking. International Journal of Science Education, 33, 1289-1312.

Allchin, D. (2000). Mending Mendelism. American Biology Teacher, 62, 633-639.

Allchin, D. (2005). The dilemma of dominance. Biology and Philosophy, 20, 427-451.

Anderson, D.L., Fisher, K.M. \& Norman, G.J. (2002). Development and evaluation of the Conceptual Inventory of Natural Selection. Journal of Research in Science Teaching, 39, 952-978.

Andrews, T.M., Price, R.M., Mead, L.S., McElhinny, T.L., Thanukos, A., Perez, K.E. et al. (2012). Biology undergraduates' misconceptions about genetic drift. CBE Life Sciences Education, 11, 248-259.

Baum, D.A., Smith, S.D. \& Donovan, S.S.S. (2005). The tree-thinking challenge. Science, 310, 979-980.

Beggrow, E.P. \& Nehm, R.H. (2012). Students' mental models of evolutionary causation: natural selection and genetic drift. Evolution: Education and Outreach, 5, 429-444.

Bowling, B.V., Acra, E.E., Wang, L., Myers, M.F., Dean, G.E., Markle, G.C., Moskalik, C.L. \& Huether, C.A. (2008a). Development and evaluation of a genetics literacy assessment instrument for undergraduates. Genetics, 178, 15-22.

Bowling, B.V., Huether, C.A., Wang, L., Myers, M.F., Markle, G.C., Dean, G.E. et al. (2008b). Genetic literacy of undergraduate non-science majors and the impact of introductory biology and genetics courses. BioScience, 58, 654-660.

Brownell, S.E., Freeman, S., Wenderoth, M.P. \& Crowe, A.J. (2014). BioCore Guide: a tool for interpreting the core concepts of Vision and Change for biology majors. CBE Life Sciences Education, 13, 200-211.

Christensen, A.C. (2000). Cats as an aid to teaching genetics. Genetics, 155, 999-1004.

Clement, J. (1993). Usinģ bridģing analoģies and anchoring intuitions to deal with students' preconceptions in physics. Journal of Research in Science Teaching, 30, 1241-1257.

Coddington, J.A. (1988). Cladistic tests of adaptational hypotheses. Cladistics, 4, 3-22.

Colleģe Board (2012). AP Biology: Course and Exam Description. New York, NY: College Board.

Collins, A. \& Stewart, J.H. (1989). The knowledge structure of Mendelian genetics. American Biology Teacher, 51, 143-149.

Crowther, G.J. \& Price, R.M. (2014). Re: Misconceptions are "so yesterday!" CBE Life Sciences Education, 13, 3-5.

Darwin, C.R. (1859). On the Origin of Species by Means of Natural Selection. London: John Murray.

D’Avanzo, C. (2008). Biology concept inventories: overview, status, and next steps. BioScience, 58, 1079-1085.

Donovan, M.P. (1997). The vocabulary of biology and the problem of semantics. Journal of College Science Teaching, 26, 381-382.

Fisher, K.M. \& Williams, K.S. (2014). Concept inventories/conceptual assessments in biology (CABs): an annotated list. Available online at http://go.sdsu.edu/dus/ctl/cabs.aspx.
Gould, S.J. \& Lewontin, R.C. (1979). The spandrels of San Marco and the Panglossian paradigm: a critique of the adaptationist programme. Proceedings of the Royal Society B, 205, 581-598.

Gregory, T.R. (2009). Understanding natural selection: essential concepts and common misconceptions. Evolution: Education and Outreach, 2, 156-175.

Heim, W.G. (1991). What is a recessive allele? American Biology Teacher, 53, 94-97.

Hiatt, A., Davis, G.K., Trujillo, C., Terry, M., French, D.P., Price, R.M. \& Perez, K.E. (2013). Getting to evo-devo: concepts and challenges for students learning evolutionary developmental biology. CBE Life Sciences Education, 12, 494-508.

Jakobi, S.R. (2010). "Little monkeys on the grass. .." How people for and against evolution fail to understand the theory of evolution. Evolution: Education and Outreach, 3, 416-419.

Kampourakis, K. \& Minelli, A. (2014). Evolution makes more sense in light of development. American Biology Teacher, 76, 493-498.

Laland, K., Uller, T., Feldman, M., Sterelny, K., Müller, G.B., Moczek, A. et al. (2014). Does evolutionary theory need a rethink? Nature News, 514, 161-164.

Leonard, M.J., Kalinowski, S.T. \& Andrews, T.C. (2014). Misconceptions yesterday, today, and tomorrow. CBE Life Sciences Education, 13, 179-186.

Linde-Medina, M. \& Diogo, R. (2014). Do correlation patterns reflect the role of development in morphological evolution? Evolutionary Biology, 41, 494-502.

Maskiewicz, A.C. \& Lineback, J.E. (2013). Misconceptions are "so yesterday!" CBE Life Sciences Education, 12, 352-356.

Moharreri, K., Ha, M. \& Nehm, R.H. (2014). EvoGrader: an online formative assessment tool for automatically evaluating written evolutionary explanations. Evolution: Education and Outreach, 7, 15

Nadelson, L.S. \& Southerland, S.A. (2010). Development and preliminary evaluation of the Measure of Understanding of Macroevolution: introducing the MUM. Journal of Experimental Education, 78, 151-190.

National Research Council (2012). A Framework for K-12 Science Education: Practices, Crosscutting Concepts, and Core Ideas. Washinģton, DC: National Academies Press.

Nehm, R.H., Beggrow, E.P., Opfer, J.E. \& Ha, M. (2012). Reasoning about natural selection: diagnosing contextual competency using the ACORNS instrument. American Biology Teacher, 74, 92-98.

Nehm, R.H., Ha, M., Rector, M., Opfer, J., Perrin, L., Ridgwway, J. \& Mollohan K. (2010). Scoring guide for the Open Response Instrument (ORI) and Evolutionary Gain and Loss Test (EGALT). Technical Report of National Science Foundation REESE Project 0909999. Available online at http:// citeseerx.ist.psu.edu/viewdoc/download;jsessionid=A14C95624D9CFE7 089B30827BAFD8F7F?doi=10.1.1.471.7384\&rep=repl\&type=pdf.

Nehm, R.H. \& Reilly, L. (2007). Biology majors' knowledģe and misconceptions of natural selection. BioScience, 57, 263-272.

Nehm, R.H. \& Schonfeld, I.S. (2008). Measuring knowledge of natural selection: a comparison of the CINS, an open-response instrument, and an oral interview. Journal of Research in Science Teaching, 45, 1131-1160.

Nielsen, R. (2009). Adaptionism - 30 years after Gould and Lewontin. Evolution, 63, 2487-2490.

Novick, L.R. \& Catley, K.M. (2012). Assessing students' understanding of macroevolution: concerns regarding the validity of the MUM. International Journal of Science Education, 34, 2679-2703.

Perez, K.E., Hiatt, A., Davis, G.K., Trujillo, C., French, D.P., Terry, M. \& Price, R.M. (2013). The EvoDevoCl: a concept inventory for ģauģing students' understanding of evolutionary developmental biology. CBE Life Sciences Education, 12, 665-675.

Pigliucci, M. \& Kaplan, J. (2000). The fall and rise of Dr Pangloss: adaptationism and the Spandrels paper 20 years later. Trends in Ecology \& Evolution, 15, 66-70. 
Piggliucci, M. \& Müller, G.B. (2010). Evolution: The Extended Synthesis. Cambridgge, MA: MIT Press.

Price, R.M., Andrews, T.C., McElhinney, T.L., Mead, L.S., Abraham, J.K., Thanukos, A. \& Perez, K.E. (2014). The Genetic Drift Inventory: a tool for measuring what advanced undergraduates have mastered about genetic drift. CBE Life Sciences Education, 13, 65-75.

Redfield, R.J. (2012). "Why do we have to learn this stuff?" - a new genetics for 21st century students. PLoS Bioloğy, 10, el001356.

Rohrer, D. (2012). Interleaving helps students distinguish among similar concepts. Educational Psychology Review, 24, 355-367.

Singer, S.R., Nielsen, N.R. \& Schweingruber, H.A. (Eds.) (2012). DisciplineBased Education Research: Understanding and Improving Learning in Underģraduate Science and Enogineerinğ. Washinģton, DC: National Academies Press.
Smith, J.I. \& Tanner, K. (2010). The problem of revealing how students think: concept inventories and beyond. CBE Life Sciences Education, 9, 1-5.

Smith, M.K. \& Knight, J.K. (2012). Using the genetics concept assessment to document persistent conceptual difficulties in undergraduate genetics courses. Genetics, 181, 21-32.

Smith, M.K., Wood, W.B. \& Knight, J.K. (2008). The Genetics Concept Assessment: a new concept inventory for gaugging student understanding of genetics. CBE Life Sciences Education, 7, 422-430.

REBECCA M. PRICE is an Associate Professor at the University of Washington Bothell, Bothell, WA 98011; e-mail: beccap@uw.edu. KATHRYN E. PEREZ is an Assistant Professor at the University of Texas Rio Grande Valley, Edinburg,, TX 78539; e-mail: perezke@gmail.com.

\section{Appendix. Concept Inventories - What Are They \& How Can We Use Them to Improve Instruction?}

Concept inventories (CIs) are tools used to understand how different populations of students think and to compare the efficacy of different teaching strategies (Smith \& Tanner, 2010). Instructors can use them to gauge which misconceptions are prevalent in their classes (Nehm \& Schonfeld, 2008; Smith \& Tanner, 2010) and then choose the techniques that are most effective for their unique groups of students (D'Avanzo, 2008).

Because CIs are usually forced-response instruments, typically multiple-choice or true-false, instructors can use them to rapidly assess conceptual understanding of evolution in large numbers of students. They can usually be completed quickly, in about 15-30 minutes of class or homework time, and they can be scored quickly as well.

Each question in a CI targets a key concept and one or more common misconceptions - inaccuracies that students have about a concept (Crowther \& Price, 2014) and that reflect where their understanding begins. The term misconceptions has been controversial, because to some it ignores or diminishes the value of the students' prior knowledge (Maskiewicz \& Lineback, 2013; Crowther \& Price, 2014; Leonard et al., 2014). Nonetheless, we feel that the term is an easy-to-understand description of how inaccuracies can inhibit mastery of a key concept.

The answer choices in CIs that contain misconceptions are often called distractors (D'Avanzo, 2008; Smith \& Tanner, 2010). If these responses are chosen, it indicates that students retain inaccurate, non-expert-like thinking. By looking at students' responses, instructors can assess whether students in their classes have persistent difficulties with a particular concept (e.g., Smith \& Knight, 2012).

At first glance, CIs seem like exams, but they are actually quite different (D'Avanzo, 2008). First, the language used in the questions and answers is carefully vetted to ensure that the instrument assesses concepts rather than vocabulary. This vetting involves several rounds of interviews and surveys across diverse student populations (Adams \& Wieman, 2011). Second, the distractors are carefully chosen to highlight common misconceptions; the question juxtaposes accurate understanding with inaccurate understanding, so students must decide which perspective makes the most sense to them. Third, they are intended to be used for formative, rather than only summative, assessment; instructors can use the results to adjust their approach to teaching (D’Avanzo, 2008).

Recently, the kinds of tools available for rapidly assessing student understanding of evolution have been increasing. Nehm and colleagues have developed an open-ended instrument for assessing students' short explanations of natural selection occurring under different conditions (Nehm et al., 2012). They have released the "EvoGrader," a web-based portal that automatically scores students' essays about natural selection (Moharreri et al., 2014). Nehm's work is a glimpse into a future when we have instruments for assessing students' understanding of a breadth of evolutionary processes in a variety of contexts.

Various CIs now exist for undergraduate biology education (archived at Fisher \& Williams, 2014), and AAAS houses assessment questions for high school students (AAAS, 2015), among which are increasing numbers of CIs about evolution (see Fisher \& Williams, 2014). However, more CIs are necessary to assess the breadth of evolutionary processes about which students learn. 